\title{
pH, CONDUTIVIDADE ELÉTRICA E POTÁSSIO DO SOLO APÓS TRÊS ANOS DE APLICAÇÕES DE NITROGÊNIO E POTÁSSIO EM AMEIXEIRA, NO MUNICÍPIO DE ARAUCÁRIA - PR ${ }^{1}$
}

\author{
pH, ELETRIC CONDUCTIVITY AND LEVELS POTASSIUM THIS SOIL \\ AFTER THREE YEARS APLLIEDS NITROGEN AND POTASSIUM AT THIS \\ PLUM, AT ARAUCARIA COUNTY PARANA - BRAZIL
}

\author{
Marcos Antonio DOLINSKI ${ }^{2}$ \\ Antonio Carlos Vargas MOTTA ${ }^{3}$ \\ Beatriz Monte SERRAT ${ }^{3}$ \\ Louise Larissa MAY-DE MIO ${ }^{4}$
}

\begin{abstract}
RESUMO
O objetivo deste trabalho foi avaliar após três anos de aplicações de adubações potássica e nitrogenada para a cultura da ameixeira (Prunus salicina), cultivar 'Reubennel', o efeito no pH, na condutividade elétrica e na concentração de potássio do solo, na projeção da copa e no centro da rua. O experimento foi realizado em Araucária (PR) e teve delineamento experimental em parcela sub-subdividida com três repetições, distribuídos em parcelas sub-subdivididas. Na parcela foi aplicado o potássio (55 e $110 \mathrm{~kg}_{\text {de K}} \mathrm{O} \mathrm{ha}^{-1}$ ano $^{-1}$ ), e na subparcela o nitrogênio (40, 80, 120, $160 \mathrm{e} 200 \mathrm{~kg} \mathrm{de} \mathrm{N} \mathrm{ha}^{-1}$ ano $^{-1}$ ), durante as safras de 2003, 2004 e 2005, em solo do tipo Cambissolo não irrigado. O solo foi analisado na projeção da copa e centro da rua como sub-subparcela. Três anos de diferentes doses de adubação nitrogenada e potássica, não apresentaram efeito no $\mathrm{pH}$, na condutividade elétrica e no $\mathrm{K}$ do solo. $\mathrm{O} \mathrm{pH}$ do solo apresentou variação entre 5,6 a 6,1 , até $40 \mathrm{~cm}$ de profundidade, não sendo alterado pela aplicação de nitrogênio, possivelmente efeito combinado da fonte e do tempo, a baixa capacidade de acidificação da fonte de $\mathrm{N}$ utilizada (uréia), e o efeito residual da aplicação do calcário utilizado na implantação do pomar. O K disponível no solo era alto e não foi influenciado pelas doses de $\mathrm{K}$ aplicadas durante três anos. Os valores de $\mathrm{pH}$, de condutividade elétrica e de $\mathrm{K}$ do solo, maiores na projeção da copa quando comparados ao centro da rua, podem ser explicados pela concentração de fertilizante e calcário na projeção da copa.
\end{abstract}

Palavras-chave: ameixa; fertilidade do solo; uréia.

\begin{abstract}
The objective of this research aim was to evaluate after tree years nitrogen and potassium fertilization of plum (Prunus salicina), cv. 'Reubennel', this effect in the $\mathrm{pH}$, conductive electric and levels potassium this soil, in the projection ray and middle alley. The experiment was conducted in Araucaria (Brazil) and design was a split-plot in a randomized complete block with three replications. Main plot treatments were potassium rates ( 55 and $110 \mathrm{~kg}$ of $\mathrm{K}_{2} \mathrm{O} \mathrm{ha}{ }^{-1} \mathrm{ano}^{-1}$ ), and subplot treatments were the nitrogen rates $\left(40,80,120,160\right.$ and $200 \mathrm{~kg}$ of N ha ${ }^{-1}$ ano-1), during the seasons 2003, 2004 and 2005, in the soil type Cambisol not irrigated. The place of collection of the soil under the canopy and in the middle alley, were analyzed was analyzed as split-split plot. Three years of different rates of nitrogen and potassium, was not effect of $\mathrm{pH}$, electrical conductivity and $\mathrm{K}$ in the soil. The soil pH ranged from 5.6 to 6.1 until $40 \mathrm{~cm}$ depth, was not influenced by $\mathrm{N}$ application, due to combined effect of sort-term application, low potential acidification of $\mathrm{N}$ source (urea), and residual effect of large application of limestone at orchard establishment. Soil available $\mathrm{K}$ was also high and was not influenced by levels $\mathrm{K}$ applications during three years. Higher values for soil $\mathrm{pH}$, electric conductivity and $\mathrm{K}$ from samples collected canopy compared to middle alley, can explain the results for localized application of limestone and fertilizer on canopy area.
\end{abstract}

Key-words: plum; soil fertility; urea.

\footnotetext{
${ }^{1}$ Parte da Dissertação de Mestrado do primeiro autor apresentada ao Departamento de Solos e Engenharia Agrícola da Universidade Federal do Paraná (UFPR).

${ }^{2}$ Eng. Agr., MSc. Ciência do Solo - Universidade Federal do Paraná (UFPR), Doutorando do Departamento de Fitotecnia e Fitossanitarismo da Universidade Federal do Paraná (UFPR) Curitiba, Paraná, Brasil. e-mail: marcosagro@pop.com.br

${ }^{3}$ Eng. Agr., Dr.(a), Professor(a) do Departamento de Solos e Engenharia Agrícola da Universidade Federal do Paraná (UFPR), Rua dos Funcionários, 1540, Bairro Juvevê, Curitiba-PR - CEP 80035-050, Curitiba, Paraná, Brasil. e-mail: mottaacv@ufpr.br Autor para correspondência; e-mail: bmserrat@ufpr.br

${ }^{4}$ Eng. Agr., Dra., Professora do Departamento de Fitotecnia e Fitossanitarismo da Universidade Federal do Paraná (UFPR). Curitiba, Paraná, Brasil. e-mail: maydemio@ufpr.br
} 
DOLINSKI, M.A. et al. pH, condutividade elétrica e potássio do solo...

\section{INTRODUÇÃO}

A crescente demanda mundial por alimentos foi acompanhada por aumento da exigência dos consumidores por produtos de qualidade e cada vez mais preocupados com a preservação dos recursos naturais. Neste contexto a preocupação com relação à época, quantidade e forma de aplicação dos fertilizantes e corretivos, não se limita aos seus efeitos sobre a produção, mas também na qualidade do alimento produzido e o efeito sobre o meio ambiente: solo, água e ar (Motta et al., 2004).

As adubações em pomares de fruteiras de caroço de clima temperado são aplicadas sob a projeção da copa das plantas, sendo os nutrientes concentrados em aproximadamente $50 \%$ da área total utilizada pela cultura, essas quantidades de nutrientes aplicadas devem ser monitoradas na planta, no solo e na água.

A aplicação de nitrogênio nas formas amoniacais e amídicas, entre elas a uréia, resultam em acidificação após a oxidação por microorganismos (nitrificação). Pavan (1995) observou alta acidez em cultivos perenes no local onde são aplicados os fertilizantes, sobretudo os nitrogenados, reduzindo o desenvolvimento do sistema radicular em macieira, podendo prejudicar a nutrição das plantas e causar distúrbios fisiológicos.

A utilização de calcário para a neutralização da acidificação, mesmo em superfície sem o revolvimento no solo, tal como ocorre com as frutíferas após a sua instalação, tem apresentado resultados satisfatórios como os já observados em plantio direto e em pastagens (Motta et al., 2004).

Além do efeito benéfico dos nutrientes quando absorvidos pelas raízes, parte desses ainda podem ser lixiviado, seja naturalmente pelo processo de percolação da água ou agravado em períodos de chuvas concentradas, contaminando assim o lençol freático e acarretando a eutrofização de rios ou lagos. Em fruteiras de caroço de clima temperado o uso de fertilizantes deve ser baseado na análise de solo, de folhas, bem como no crescimento dos ramos produtivos, assim minimizando o risco de contaminação ambiental por excesso de fertilizantes, principalmente os nitratos (Fachinello \& Herter, 2000).
O objetivo deste trabalho foi avaliar após três anos de aplicações de adubações nitrogenada e potássica o efeito no $\mathrm{pH}$, na condutividade elétrica e na concentração de potássio do solo, na projeção da copa e no centro da rua.

\section{MATERIAL E MÉTODOS}

O experimento foi instalado em junho de 2003, em um pomar de ameixeira (Prunus salicina Lindl, cultivar 'Reubennel'), com quatro anos de idade, localizado no Município de Araucária, com altitude média de $900 \mathrm{~m}$ e o clima classificado como $\mathrm{Cfb}$, subtropical úmido (Koppen), com temperatura média na primavera e verão de $19,5^{\circ} \mathrm{C}(14,0$ a 23,1 ${ }^{\circ} \mathrm{C}$ ) e precipitação mensal média na primavera e verão de $126 \mathrm{~mm}$ (52,5 a $217 \mathrm{~mm})$, e no outono e inverno com temperatura média de $16,8{ }^{\circ} \mathrm{C}(13,2$ a $\left.22,6{ }^{\circ} \mathrm{C}\right)$, e precipitação acumulada mensal média de $89 \mathrm{~mm}$ (18,6 a $165 \mathrm{~mm})$.

$\mathrm{Na}$ implantação do pomar foi aplicado calcário em área total e a adubação de manutenção utilizada até a instalação do experimento foi a dose equivalente a $80 \mathrm{~kg}$ de $\mathrm{N} \mathrm{ha}^{-1} \mathrm{ano}^{-1}$ (uréia) e $80 \mathrm{~kg}$ de $\mathrm{K} \mathrm{ha}^{-1} \mathrm{ano}^{-1}$ (cloreto de potássio), na projeção da copa, sem aplicação de calcário na adubação de manutenção.

O experimento foi instalado no município de Araucária (PR), com altitude média de $900 \mathrm{~m}$ e o clima classificado como $\mathrm{Cfb}$, subtropical úmido (Koppen), com temperatura média na primavera e verão de $19,5^{\circ} \mathrm{C}\left(14,0\right.$ a $\left.23,1{ }^{\circ} \mathrm{C}\right)$ e precipitação mensal média na primavera e verão de $125,9 \mathrm{~mm}$ (52,5 a $217 \mathrm{~mm})$, e no outono e inverno com temperatura média de $16,8{ }^{\circ} \mathrm{C}\left(13,2\right.$ a $\left.22,6{ }^{\circ} \mathrm{C}\right)$, e precipitação acumulada mensal média de $88,5 \mathrm{~mm}$ (18,6 - 165,1 mm). A área apresentava solo do tipo Cambissolo, não irrigado, e as análises química e granulométrica do solo, anteriormente a instalação do experimento, estão apresentadas na Tabela 1.

$O$ delineamento experimental utilizado foi

em blocos ao acaso, com três repetições, distribuído em parcelas sub-subdivididas com cinco plantas cada, sendo três plantas na parcela útil. Os tratamentos consistiram de adubações cinco doses de nitrogênio, duas de potássio e dois locais de coleta das análises de solo.

TABELA 1 - Análise química e granulométrica do solo, em pomar de ameixeira 'Reubennel' na da projeção da copa (PC) e no centro da rua (Rua), nas profundidades de 0-20 e 20-40 cm, em junho de 2003 (Araucária - PR).

\begin{tabular}{|c|c|c|c|c|c|c|c|c|c|c|c|c|c|c|c|}
\hline \multirow[t]{2}{*}{ Local } & \multirow{2}{*}{$\begin{array}{c}\text { Prof. }^{\top} \\
\mathrm{cm}\end{array}$} & $\mathrm{pH}$ & $\mathrm{Al}^{+3}$ & $1+\mathrm{Al}^{+3}$ & $\mathrm{Mg}^{+2}$ & $\mathrm{Ca}^{+2}$ & $\mathrm{~K}^{+}$ & $\mathrm{T}^{2}$ & \multirow{2}{*}{$\begin{array}{c}\mathrm{P}^{3} \\
\mathrm{mg} \mathrm{dm^{-3 }}\end{array}$} & \multirow{2}{*}{$\begin{array}{c}\text { M.O. } \\
\text { dag dm }\end{array}$} & \multirow{2}{*}{$\begin{array}{c}\mathrm{pH} \\
\text { SMP }\end{array}$} & \multirow{2}{*}{$\begin{array}{l}\mathrm{V}^{5} \\
\%\end{array}$} & \multirow{2}{*}{\multicolumn{2}{|c|}{$\begin{array}{l}\text { Areia Silte } \\
\text {--------dag kg }\end{array}$}} & \multirow[t]{2}{*}{ Argila } \\
\hline & & $\mathrm{CaCl}_{2}$ & & & & & & & & & & & & & \\
\hline $\mathrm{PC}$ & $00-20$ & 5,5 & 0 & 3,2 & 1,96 & 4,03 & 0,59 & 9,78 & & 2,68 & 6,60 & 67 & 55 & 25 & 20 \\
\hline PC & $20-40$ & 5,4 & 0 & 3 & 2,01 & 3,73 & 0,30 & 9,44 & & 2,27 & 6,5 & 6 & 53 & 28 & 19 \\
\hline Rua & $00-20$ & 5,3 & 0 & 3,6 & 2,94 & 3,73 & 0,20 & 10,47 & 18,53 & 2,41 & 6,40 & 6 & 56 & 25 & 19 \\
\hline Rua & $20-40$ & 5,2 & 0 & 3,6 & 3,08 & 3,68 & 0,09 & 10,45 & 9,77 & 2,00 & 6,40 & 66 & 50 & 28 & 22 \\
\hline
\end{tabular}

Prof. Profundidade da coleta ${ }^{2} \mathrm{~T}=\mathrm{CTC}{ }^{3} \mathrm{P}$ Extrator Mehlich. ${ }^{4} \mathrm{M}$.O.=Matéria orgânica. ${ }^{5} \mathrm{~V}=$ Saturação de bases. 
DOLINSKI, M.A. et al. pH, condutividade elétrica e potássio do solo...

Os tratamentos de adubações foram aplicados durante as safras de 2003, 2004 e 2005, as doses de potássio foram aplicadas na parcela principal nas concentrações de 55 e $110 \mathrm{~kg}$ de $\mathrm{K}_{2} \mathrm{O}$ $\mathrm{ha}^{-1} \mathrm{ano}^{-1}$, na forma de cloreto de potássio, parcelado durante o início da brotação $(60 \%)$ e após o raleio (40\%). O nitrogênio foi aplicado na subparcela, nas doses de 40, 80, 120, 160 e $200 \mathrm{~kg}$ de $\mathrm{N}$ ha $^{-1} \mathrm{ano}^{-1}$, na forma de uréia, parcelado durante o início da brotação $(30 \%)$, após o raleio $(30 \%)$ e após a colheita (40\%), as adubações foram realizadas manualmente à lanço. A menor dose de $K$ utilizada é a recomendada pelas normas da Produção Integrada de Pessegueiro (PIF - PR $\mathrm{CNPq}, 2003$ ). Para o $\mathrm{N}$ a maior dose fica próxima da utilizada pelos produtores da região, já a dose de $80 \mathrm{~kg}$ de $\mathrm{N} \mathrm{ha}^{-1}$, era a dose recomendada pela Produção Integrada de Pessegueiro. O parcelamento das mesmas foram de acordo com as normas da Produção Integrada de Pessegueiro (PIF - PR CNPq, 2003).

$\mathrm{O}$ outro tratamento consistiu de dois locais de coleta do solo, na projeção da copa (PC) e no centro da rua (RUA), após o terceiro ano de tratamentos com as adubações que foram realizadas na $\mathrm{PC}$, e foram analisados como subsubparcela. Para cada subparcela correspondente a $18 \mathrm{~m}^{2}$, foram coletadas cinco subamostras simples nas profundidades de $0-5,5-10,10-20$ e $20-40$ $\mathrm{cm}$, na PC e na RUA, que foram homogeneizadas e acondicionadas em sacos plásticos de $500 \mathrm{~g}$ separadamente. Para a retirada das amostras nas duas primeiras profundidades foi utilizado o calador e para as demais profundidades o trado holandês.

$\mathrm{O} \mathrm{pH}$ do solo foi determinado em solução $\mathrm{CaCl}_{2} \quad 0,01 \mathrm{~mol} \mathrm{dm}^{-3}$, utilizando recepiente de plástico de $80 \mathrm{~cm}^{3}$, se transferiu $10 \mathrm{~cm}^{3}$ de TFSA e $25 \mathrm{~cm}^{3}$ de solução de $\mathrm{CaCl}_{2} 0,01 \mathrm{~mol} \mathrm{dm}^{-3}$, em seguida se agitou a solução durante $15 \mathrm{~min}$ em agitador horizontal circular. Após permanecer por $30 \mathrm{~min}$ em repouso, foram novamente agitados durante $10 \mathrm{~s}$ com bastão de vidro, em seguida se realizou a leitura em pHmetro $\left(\mathrm{pH}\right.$-meter $\left.\mathrm{E} 350 \mathrm{~B}^{\circledR}\right)$, adaptado de Marques \& Motta (2003).

A condutividade elétrica foi analisada em solução $1: 2$, transferindo-se $20 \mathrm{~cm}^{3}$ de terra fina seca ao ar (TFSA) para um recipiente plástico de 80 $\mathrm{cm}^{3}$, adicionando $40 \mathrm{~cm}^{3}$ de água deionizada, agitando manualmente com bastão de vidro durante um minuto, permanecendo em repouso por $30 \mathrm{~min}$ e em seguida foi realizada a leitura, sem agitar, utilizando o condutivímetro handylab LF ${ }^{\circledR}$ (Smith \& Doran, 1996).

O potássio foi analisado transferindo $10 \mathrm{~cm}^{3}$ de TFSA para erlenmeyer de $125 \mathrm{~cm}^{3}$, adicionandose $100 \mathrm{~cm}^{3}$ de solução de Mehlich e agitando durante $5 \mathrm{~min}$ em agitador horizontal circular. Depois de decantar por doze horas, a leitura de potássio foi realizada na amostra de $20 \mathrm{~cm}^{3}$ da solução sobrenadante, utilizando fotômetro de chama Digmed NK-2000 ${ }^{\circledR}$ (Marques \& Motta, 2003).

Os resultados obtidos foram submetidos a análise de variância e as médias comparadas pelo teste de Tukey, ao nível de $5 \%$ de probabilidade, utilizando $\mathrm{o}$ aplicativo computacional MSTATC ${ }^{\circledR}$ (Freed, 1994).

\section{RESULTADOS E DISCUSSÃO}

A análise de solo geral realizada na instalação do experimento para a caracterização do solo, realizadas na projeção da copa (PC) e no centro da rua (RUA), apresentaram tendência de variações entre os locais de coleta (Tabela 1). O pomar vinha sendo conduzido pelo produtor com uma dose única de adubação, equivalente a $80 \mathrm{~kg}$ de $\mathrm{N} \mathrm{ha}{ }^{-1} \mathrm{ano}^{-1}$ e $80 \mathrm{~kg}$ de $\mathrm{K}_{2} \mathrm{O} \mathrm{ha}$ h $^{-1}$ ano $^{-1}$, as mesmas eram realizadas a lanço concentradas na projeção da copa.

Em relação aos tratamentos de diferentes doses de adubação nitrogenada e potássica aplicadas durante três anos, em pomar de ameixeira a partir do quarto ano de implantação, não promoveram variações no $\mathrm{pH}$, na condutividade elétrica e na concentração de potássio do solo (Tabela 2).

Mesmo com a utilização de doses maiores do que ao dobro da que vinha sendo utilizada pelo produtor, concentradas na projeção da copa durante três anos, não promoveram redução do $\mathrm{pH}$ neste local nas diferentes profundidades analisadas, ficando maiores do que os observados no centro da rua (Tabela 3 ).

TABELA 2 - pH, condutividade elétrica e potássio do solo, em um pomar de ameixeira 'Reubennel', em 2006, após três anos de diferentes doses de adubação nitrogenada e potássica, média das três coletas de 0 a $20 \mathrm{~cm}$ de profundidade na projeção da copa (PC) (Araucária - PR).

\begin{tabular}{|c|c|c|c|c|c|c|c|c|c|c|}
\hline \multirow[t]{2}{*}{ Análise } & \multicolumn{2}{|c|}{$40 N^{2}$} & \multicolumn{2}{|c|}{$80 \mathrm{~N}$} & \multicolumn{2}{|c|}{$120 \mathrm{~N}$} & \multicolumn{2}{|c|}{$160 \mathrm{~N}$} & \multicolumn{2}{|c|}{$200 \mathrm{~N}$} \\
\hline & $55 \mathrm{~K}^{3}$ & $110 \mathrm{~K}$ & $55 \mathrm{~K}$ & $110 \mathrm{~K}$ & $55 \mathrm{~K}$ & $110 \mathrm{~K}$ & $55 \mathrm{~K}$ & $110 \mathrm{~K}$ & $55 \mathrm{~K}$ & $110 \mathrm{~K}$ \\
\hline $\mathrm{pH}^{4}$ & $5,9^{\text {ns }}$ & 6,1 & 5,8 & 5,8 & 5,7 & 5,9 & 6,0 & 6,0 & 5,8 & 5,8 \\
\hline$K^{6}$ & $\begin{array}{c}90^{\mathrm{ns}} \\
0,41^{\mathrm{ns}}\end{array}$ & $\begin{array}{c}88 \\
0,45\end{array}$ & $\begin{array}{c}69 \\
0,48\end{array}$ & $\begin{array}{c}86 \\
0,42\end{array}$ & $\begin{array}{c}88 \\
0,43\end{array}$ & $\begin{array}{c}72 \\
0,51\end{array}$ & $\begin{array}{c}84 \\
0,50\end{array}$ & $\begin{array}{c}87 \\
0,44\end{array}$ & $\begin{array}{c}89 \\
0,52\end{array}$ & $\begin{array}{c}75 \\
0,39\end{array}$ \\
\hline
\end{tabular}

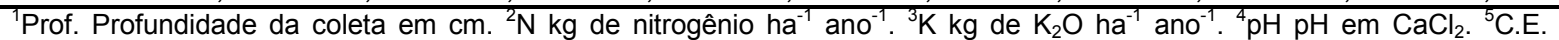
condutividade elétrica em $\mu \mathrm{S} \mathrm{cm}^{-1}$. ${ }^{6} \mathrm{~K}$ potássio em $\mathrm{cmol}_{\mathrm{c}} \mathrm{dm}^{-3}$. ns não significativo ao nível de $95 \%$ de probabilidade. 
DOLINSKI, M.A. et al. pH, condutividade elétrica e potássio do solo...

TABELA 3 - pH do solo $\left(\mathrm{CaCl}_{2}\right)$, na projeção da copa (PC) e no centro da rua (RUA), em um pomar de ameixeira 'Reubennel', em 2006, após três anos de diferentes doses de adubação nitrogenada e potássica (Araucária - PR).

\begin{tabular}{ccccc}
\hline $\begin{array}{c}\text { Profundidade } \\
(\mathrm{cm})\end{array}$ & PC & RUA & Média & C.V.(\%) $)^{1}$ \\
\hline $0-05$ & $5,8 \mathrm{a}$ & $5,7 \mathrm{~b}$ & 5,8 & 3,0 \\
$05-10$ & $5,9 \mathrm{a}$ & $5,7 \mathrm{~b}$ & 5,8 & 3,4 \\
$10-20$ & $5,9 \mathrm{a}$ & $5,8 \mathrm{~b}$ & 5,9 & 2,9 \\
$20-40$ & $5,9 \mathrm{a}$ & $5,7 \mathrm{~b}$ & 5,8 & 2,8 \\
\hline Média & 5,9 & 5,7 & 5,8 &
\end{tabular}

${ }^{1}$ C.V.(\%) Coeficiente de variação. Médias seguidas da mesma letra, na linha, não diferem entre si, pelo teste de Tukey, ao nível de $5 \%$ de probabilidade.

Possivelmente a quantidade de corretivos utilizada no pomar foi suficiente para corrigir a acidez inicial e a promovida pelas diferentes doses de $\mathrm{N}$ utilizadas durante os três anos. Ainda, é comum assim como para os fertilizantes, o uso de corretivo aplicado em superfície e concentrados sob a projeção da copa, o que explica os maiores valores de $\mathrm{pH}$ observados nessa região.

Os pomares da região se encontram principalmente em solos derivados de rochas sedimentares, apresentando elevada acidez e baixa disponibilidade de nutrientes. Em levantamento realizado na região, cerca de $40 \%$ dos pomares apresentaram $\mathrm{pH}$ baixo ou muito baixo para a profundidade de $0-20 \mathrm{~cm}$, e em $80 \%$ deles entre $20-40 \mathrm{~cm}$ de profundidade (Oliveira \& Tsuneta, 1987).

Assim é provável que $\mathrm{o}$ elevado $\mathrm{pH}$ observado para esse solo, mesmo em profundidade, possa estar relacionado à aplicação e incorporação em profundidade de corretivo, prática comum aos produtores de elevada tecnologia na região, anteriormente a instalação do pomar. A intenção da aplicação e incorporação em profundidade é favorecer o crescimento das raízes e estabelecimento da cultura. Como as doses inicialmente utilizadas de corretivos são elevadas para atingir níveis compatíveis ao crescimento das plantas, pode-se esperar efeito residual prolongado, superior a décadas.

Em longo prazo já foram observados que aplicações bianuais de pequenas doses de corretivo em superfície possibilita a manutenção desse $\mathrm{pH}$ corrigido, mesmo em profundidade (Motta et al., 2004), fato constatado em pastagens (Brown et al., 1956), em fruticultura (Smith, 1996) e em plantio direto e convencional (Gascho \& Parker, 2001).

$\mathrm{O} \mathrm{pH}$ observado próximo a $6,0 \mathrm{em} \mathrm{CaCl}_{2}$ poderia determinar a existência de granulo de calcário no solo, visto que o acúmulo de frações de calcário vem sendo observada em solos com $\mathrm{pH}$ acima de 6,0 em água (Allen \& Hossner, 1991), o que pode ter contribuído para ausência de variação no $\mathrm{pH}$. Aliado a este fato, a fonte amídica (uréia) utilizada no experimento, apresenta menor poder de acidificação em comparação a outras formas de $\mathrm{N}$ disponíveis, como sulfato de amônio.

Discordando com os resultados aqui obtidos, Pavan (1992) após dez anos de aplicação de uréia em macieira, observou efeito acumulativo da uréia sobre o pH do solo na projeção da copa quando comparado às amostras do centro da rua ou da testemunha na projeção da copa. A acidificação foi dependente da quantidade de $\mathrm{N}$ aplicada, com efeito, até 40 a $60 \mathrm{~cm}$ de profundidade. Possivelmente a falta de resposta à acidificação no presente trabalho tenha sido o efeito combinado da fonte e do tempo, a baixa capacidade de acidificação da fonte de $\mathrm{N}$ utilizada (uréia) e o efeito residual da aplicação do calcário utilizado no estabelecimento de pomar.

O estudo em áreas com adubação de coqueiro anão-verde onde a adubação também é concentrada na PC, a acidificação do solo pela adubação nitrogenada se acentuou ao longo do tempo, sugerindo ao necessidade de monitoramento em áreas que recebam doses superiores a $120 \mathrm{~kg}$ de $\mathrm{N} \mathrm{ha}^{-1} \mathrm{ano}^{-1}$ (Teixeira et al., 2005), indicando que o estudo na área no presente trabalho por um período maior, poderia promover uma acidificação entre os locais de coleta e em função das doses de $\mathrm{N}$ utilizadas.

Cummings (1989) observou que entre pomares de pessegueiro implantados em condições de $\mathrm{pH}$ em $\mathrm{CaCl}_{2}$ de 4,9, 5,4 e 6,0, no maior valor de $\mathrm{pH}$ foi observado maior crescimento do tronco, maior produtividade, maior longevidade do pomar e maior concentração no teor foliar de Ca. Já, nos pomares sob condições de $\mathrm{pH}$ menor que 5,5 esses apresentaram alta saturação de $\mathrm{Al}$ e menor porcentagem de saturação de bases resultando em menor desenvolvimento das plantas de pessegueiro.

Os valores elevados de $\mathrm{pH}$ ao longo do perfil, podem ter contribuído em parte com as altas produtividades obtidas na área, o equivalente a 38,7 Mg ha ${ }^{-1}$, na média de três anos, apresentando condições favoráveis para o crescimento das raízes, aumentando a capacidade de absorção de água e nutrientes, e reduzindo a suscetibilidade de estresse hídrico em períodos de veranicos (Dolinski et al., 2007). 
DOLINSKI, M.A. et al. pH, condutividade elétrica e potássio do solo...

Para o parâmetro de condutividade elétrica, os valores na projeção da copa foram superiores para todas as profundidades estudadas, em relação ao centro da rua (Tabela 4), o aumento na concentração de prótons e ânions advindos das adubações concentradas explicam em parte essa diferença observada.

TABELA 4 - Condutividade elétrica do solo $\left(\mu \mathrm{sm}^{-1}\right)$, na projeção da copa (PC) e no centro da rua (RUA), em um pomar de ameixeira 'Reubennel', em 2006, após três anos de diferentes doses de adubação nitrogenada e potássica (Araucária - PR).

\begin{tabular}{ccccc}
\hline Profundidade $(\mathrm{cm})$ & PC & RUA & Média & C.V.(\%) $)^{1}$ \\
\hline $0-05$ & $94 \mathrm{a}$ & $90 \mathrm{~b}$ & 92 & 19,5 \\
$05-10$ & $72 \mathrm{a}$ & $57 \mathrm{~b}$ & 65 & 16,7 \\
$10-20$ & $83 \mathrm{a}$ & $67 \mathrm{~b}$ & 75 & 18,8 \\
$20-40$ & $100 \mathrm{a}$ & $81 \mathrm{~b}$ & 91 & 31,6 \\
\hline Média & 87 & 74 & 81 &
\end{tabular}

${ }^{1}$ C.V.(\%) Coeficiente de variação. Médias seguidas da mesma letra, na linha, não diferem entre si, pelo teste de Tukey, ao nível de $5 \%$ de probabilidade.

As diferenças entre os dois locais amostrados também se mantiveram em profundidade, indicando acúmulo ou estado momentâneo de maior concentração de ânion de alta mobilidade, nas camadas mais profundas. Indicando a necessidade no momento da definição das doses de fertilizantes a ser utilizado, levar em consideração além dos fatores de produtividade, desenvolvimento vegetativo e qualidade dos frutos, também o efeito sobre o meio ambiente: solo, água e ar, sobretudo o risco de perdas por lixiviação (Motta et al., 2004).
Silva (2005) observou valores semelhantes para a condutividade elétrica do solo, e também com valores maiores nos primeiros cinco centímetros de profundidade, podendo ser explicado em parte pela reciclagem dos nutrientes.

Assim como para o $\mathrm{pH}$ e a condutividade elétrica os valores de $\mathrm{K}$ do solo, foram significativamente superiores na projeção da copa quando comparado ao centro da rua (Tabela 5).

TABELA 5 - Potássio do solo $\left(\mathrm{cmol}_{\mathrm{c}} \mathrm{dm}^{-3}\right)$, na projeção da copa (PC) e no centro da rua (RUA), em um pomar de ameixeira 'Reubennel', em 2006, após três anos de diferentes doses de adubação nitrogenada e potássica (Araucária - PR).

\begin{tabular}{ccccc}
\hline Profundidade $(\mathrm{cm})$ & PC & RUA & Média & C.V.(\%) $)^{1}$ \\
\hline $0-05$ & $0,56 \mathrm{a}$ & $0,59 \mathrm{a}$ & 0,57 & 12,0 \\
$05-10$ & $0,41 \mathrm{a}$ & $0,26 \mathrm{~b}$ & 0,33 & 16,0 \\
$10-20$ & $0,40 \mathrm{a}$ & $0,17 \mathrm{~b}$ & 0,29 & 22,1 \\
$20-40$ & $0,33 \mathrm{a}$ & $0,12 \mathrm{~b}$ & 0,22 & 26,0 \\
\hline Média & 0,42 & 0,28 & 0,35 &
\end{tabular}

${ }^{1}$ C.V.(\%) Coeficiente de variação. Médias seguidas da mesma letra, na linha, não diferem entre si, pelo teste de Tukey, ao nível de $5 \%$ de probabilidade.

Nos primeiros $5 \mathrm{~cm}$ do solo, não foram observadas diferenças entre os dois locais de coleta, tal fato pode ser atribuído à reciclagem, podendo ter contribuído para manter esses valores em superfície. Para as demais profundidades, os valores de $\mathrm{K}$ se mantiveram maiores na projeção da copa quando comparado com o centro da rua, até $40 \mathrm{~cm}$ de profundidade.

A importância da reciclagem dos nutrientes observada para a condutividade elétrica, sobretudo pode ser reforçada para o $\mathrm{K}$, uma vez que aquela pode ocorrer para esse elemento pela simples lavagem da parte aérea da planta ou liberado de resíduos vegetais antes da sua decomposição, motivo pelo qual é comum a observação de concentração maior de K na superfície em relação ao perfil do solo em ambientes onde os mesmos não sofrem revolvimento (Motta et al., 2004).

A adubação potássica não apresentou efeito nas características avaliadas de produtividade, de crescimento vegetativo ou de interação com a adubação nitrogenada (Dolinski et al., 2007), essa falta de resposta pode ser explicada pelos valores altos de $\mathrm{K}$ no solo (média de $0,35 \mathrm{cmol}_{\mathrm{c}} \mathrm{dm}^{-3}$ ). Pesquisas realizadas em solos brasileiros com $\mathrm{K}$ não têm apresentado freqüentemente respostas a esse nutriente, provavelmente pelos valores adequados desse elemento prontamente disponível 
DOLINSKI, M.A. et al. pH, condutividade elétrica e potássio do solo...

para as plantas e a presença de minerais fontes de $\mathrm{K}$ a curto, médio e em longo prazo (Meurer, 2006).

Os resultados obtidos no presente trabalho servem de suporte para tomada de decisões de local de coleta para a realização da análise de solo e para a recomendação de aplicação de corretivos e fertilizantes, em pomares de fruteiras de caroço de clima temperado, observadas as concentrações de nutrientes em faixas nos pomares no local de aplicação dos corretivos e fertilizantes.

\section{CONCLUSÕES}

1) Três anos de diferentes doses de adubação nitrogenada e potássica, não apresentaram efeito no $\mathrm{pH}$, na condutividade elétrica e no $\mathrm{K}$ do solo.

2) Os valores de $\mathrm{pH}$, de condutividade elétrica e de $\mathrm{K}$ do solo foram maiores na projeção da copa quando comparados ao centro da rua.

\section{AGRADECIMENTOS}

Ao Sr. Waldomiro Gayer Neto por conceder o pomar para a instalação do experimento e por todo o apoio dado no campo para o desenvolvimento do trabalho. Ao Conselho Nacional de Desenvolvimento Científico e Tecnológico (CNPq) e ao Ministério da Agricultura, Pecuária e Abastecimento (MAPA), pelo suporte financeiro e pela concessão da bolsa de estudo.

\section{REFERÊNCIAS}

1. ALLEN, E. R.; HOSSNER, L. R. Factors affecting the accumulation of surface applied agricultural limestone in permanent pasture. Soil Science, v. 151, n. 3, p. 240-248, 1991.

2. BROWN, B. A.; MUNSELL, R.I.; HOLT, R.F.; KING, A.V. Soil reactions at various depths as influenced by time since application and amounts of limestone. Soil Science Society of America, v. 20, n. 4, p. 518-522, 1956.

3. CUMMINGS, G. A. Effect of soil $\mathrm{pH}$ and calcium amendments on peach yield, tree growth and longevity. Acta Horticulturae, v. 254, p. 179-184, 1989.

4. DOLINSKI, M. A. et al. Adubação nitrogenada e potássica na produtividade da ameixeira 'Reubennel', na região de Araucária - PR. Revista Brasileira de Fruticultura, v. 29, n. 2, p. 364-370, 2007.

5. FACHINELLO, J. C.; HERTER, F. G. Diretrizes para a produção integrada de frutas de caroço. Pelotas: Embrapa Clima Temperado, 2000. 46 p. (Circular Técnica, 19).

6. FREED, R. MSTATC Program. Michigan, 1994. Disponível em: <https://www.msu.edu/ freed/disks.htm>. Acesso em 21 Nov 2003.

7. GASCHO, G. J.; PARKER, M. B. Long-term liming effects on Coastal Plain soils and crops. Agronomy Journal, v. 93, n 6, p. 1305-1315, 2001.

8. MARQUES, R.; MOTTA, A.C.V. Análise química do solo par fins de fertilidade. In: LIMA, M. R.; SIRTOLI, A. E.; SERRAT, B. M.; WISNIEWSKI, C.; ALMEIDA, L. de; MACHADO, M. A. de M.; MARQUES, R., MOTTA, A. C. V. (Org.). Manual de diagnóstico da fertilidade e manejo dos solos agrícolas. 2. ed. rev. ampl. Curitiba: Universidade Federal do Paraná/ Departamento de Solos e Engenharia Agrícola, Projeto Solo Planta, 2003. p. 81-102

9. MEURER, J. M. Potássio. In: FERNANDES, M. S. (Ed.) Nutrição mineral de plantas. Viçosa: Sociedade Brasileira de Ciência do Solo, 2006. p. 281-298

10. MOTTA, C. V. M.; SERRAT, B. M.; FAVARETTO, N. Fertilidade do solo. In: MONTEIRO, L. B.; MAY-DE MIO, L. L; SERRAT, B. M.; MOTTA, A. C.; CUQUEL F. L. (Ed.) Fruteiras de caroço: uma visão ecológica. Curitiba: Universidade Federal do Paraná, 2004, p. 49-57.

11. OLIVEIRA, E L.; TSUNETA, M. Estado nutricional do pessegueiro na região metropolitana de Curitiba. Londrina: IAPAR, 1987. p. 1-6. (Boletim Técnico, 79).

12. PAVAN, M. A. Estratificação da acidez do solo devido a adubação nitrogenada em pomares estabelecidos de macieira. Revista Brasileira de Fruticultura, v. 14, n. 2, p. 135-138, 1992.

13. PAVAN, M. A. Efeito da adubação mineral na distribuição do sistema radicular da macieira. Revista Brasileira de Ciência do Solo, v. 19, n. 2, p. 477-480, 1995.

14. PRODUÇÃO INTEGRADA DE FRUTAS- PARANÁ- CONSELHO NACIONAL DE DESENVOLVIMENTO CIENTÍFICO E TECNOLÓGICO (PIF-PR-CNPq). Produção integrada de pêssego para o Estado do Paraná. Curitiba: UFPR, 2003. (Relatório técnico)

15. SILVA, J. C. P. M. Esterco líquido de gado de leite e adubação mineral influenciando a produção de silagem e propriedades químicas do solo na região dos Campos Gerais do Paraná. Curitiba. 63 f. Dissertação (Mestrado em Ciência do Solo) - Curso de Pós-Graduação em Ciência do Solo, Setor de Ciências Agrárias, Universidade Federal do Paraná, Curitiba, 2005.

16. SMITH, T. J. Time to re-apply lime to orchards in Washington. Better Crops, v. 80, n. 1, p. 8-9, 1996.

17. SMITH, J. L.; DORAN, J. W. Measurement and use of $\mathrm{pH}$ and electrical conductivity for soil quality analyses. In: DORAN, J. W.; JONES, A. J (Ed.). Methods for assessing soil quality. Madison: Soil Science Society of America, 1996, p. 169185. (Special Publication, 49)

18. TEIXEIRA, L. A. et al. Adubação com NPK em coqueiro anão-verde (Cocos nucifera L.) - atributos químicos do solo e nutrição da planta. Revista Brasileira de Fruticultura, v. 27, n. 1, p. 115-119, 2005.

Recebido em 31/01/2008 Aceito em 16/06/2009 